研究

\title{
温度制御半固形モールド粉体成形法によるセラミックス微小複雑構造体の作製
}

\author{
津守不二夫, 池内 駿介 \\ 京都大学大学院工学研究科マイクロエンジニアリング専攻, ₹ 606-8501 京都市左京区吉田本町.
}

\section{Fabrication of Micro Structure with Complicated Shape by Temperature Controlled Semi-solid Mold Isostatic Powder Compaction}

\author{
Fujio Tsumori and Syunsuke Ikeuchi
}

Department of Micro Engineering, Faculty of Engineering, Kyoto University, Yoshida-Honmachi, Sakyo-ku, Kyoto 606-8501, Japan.

Received July 24, 2006

\begin{abstract}
SYNOPSIS
New powder compaction process using a Bingham semi-solid/fluid mold was developed to fabricate micro parts. In the present work, a powder material was filled as slurry in a solid wax mold, dried and compressed by conventional pressing methods, such as isostatic pressing or die compaction. It is important to use slurry for filling because dry powder is hard to fill in the micro cavity. It is also essential to control the process temperature to treat micro parts. The wax mold was heated during compaction and became semi-solid state, which could acts as a pressurized medium for isostatic compaction. Since the compacted micro parts were very fragile, the mold's temperature was controlled to higher than its melting point during unloading, to avoid breakage of the compacts. To demonstrate effectiveness of the present process, some micro compacts of alumina are shown as examples.

KEY WORDS
\end{abstract}

isostatic pressing, semi-solid material, micro structure

\section{1 緒 言}

機械システムの高度化，複雑化，回路の高集積化，高速化 に伴い, 機械部品やデバイスのさらなる小型化, 高密度化が 要求されている.このような背景の下, 微小微細構造体を作 製するためのマイクロマシニング技術が注目され，これまで にさまざまな微細加工技術が提案されている.同時に微細構 造を粉末材料より作製するプロセスの提案が行われている. 本研究では複雑な成形体を割れなく得るため, 半固形状材料 を型および圧力媒体として利用する新たなプロセス ${ }^{1,2)}$ を利用 することを試みた．この方法は除荷時のモールドのスプリン グバックによる成形体のダメージを防ぐ方法であり，凹凸の 激しい形状へも応用が可能である.さらにプロセス中の温度 制御を行うことにより，スプリングバックの影響はほぼゼロ にまで下げることが可能であり ${ }^{3)}$, 脆弱なマイクロ部品にお いても粉体加圧成形が可能となると考えられる。この温度制 御プロセスとソフトMEMS (Micro Electro Mechanical Systems) 技術を応用した微細型を用い, 基板から独立した微細な構造 体を，割れや欠損なく作製することを試みた。微細な型キャ
ビティ内部に乾式の粉末を充填することは困難であるため, ここでは粉末の充填にスラリーを用いることとした.スラリー の充填から, 成形, 焼結までの一連のプロセスの開発を行い, 従来の方法では作製困難な形状のセラミックス微小複雑構造 体を加圧成形および焼結により作製した. 従来の微細構造の 作製例では粉体を型から取り出すことが困難となるため, 基 板上に微細な凹凹パターンを作製することが多かった ${ }^{4,5)}$. 本 研究での手法では型を溶融することにより, 取り出しの問題 はなくなるため基板から独立した構造を作製することが可能 であり，本論文ではこのような独立したパターンを作製する ことを考えた.

\section{2 微細構造作製プロセス}

本研究では微細な型を固形ワックスにより作製し, 粉末を 充填後, 圧縮固化し, 成形体を作製した。 その後, 成形体は 焼結され最終的な製品を得る. 本研究においては型をりフト MEMS 技術を利用して作製した. Fig.1に型の作製法を示す. ガラス基板上にスピンコートされた感光性硬化樹脂である 
SU-8を所望形状のマスクを通し露光・現像し，凹凸パターン を得る. 得られたSU-8のパターンを母型とし, シリコン樹脂 である PDMS (polydimethylsiloxane) を流しこみ固化させる. このPDMS に加熱溶融したワックスを同様に流しこみ転写 し，固形ワックスの型を作製する.PDMS はワックスとの離 型性が良好なため, このような多段階の処理を採用した。

この後スラリーを利用してキャビティにのみ粉末を充填し た. スラリーは溶媒を水としアルミナ粉末(TM-DAR: 大明化 学工業) を分散させて作製した. さらに分散材としてポリア クリル酸ソーダ(PAS)，可塑剤および成形時の潤滑材として ポリエチレングリコール (PEG)を添加した. Fig.2には充填プ ロセスの流れを示す．まず，ワックス型はエタノールに浸け られ，その後表面部を乾燥することによりキャビティ部にの みエタノールを残した状態とする.この型上にスラリーを滴 下するとFig.2内写真に示すようにキャビティの溝を通じて全 体に充填が進む. 表面に残ったスラリーの余剩分を除去し乾 燥することにより粉末の充填は完了する. 予備実験では充填 はスラリーのワックスへの濡れ性に大きく低存することが確 認されていたが，エタノールを用いることにより濡れ性に関 係なく充填を行うことが可能となった。

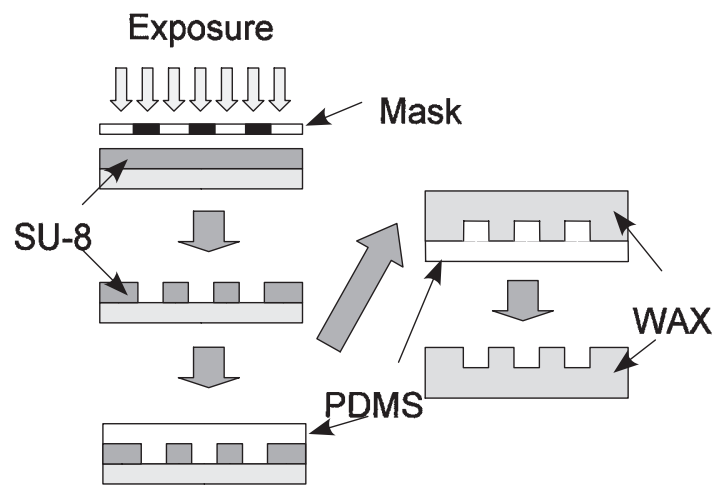

Fig.1 Flowchart of soft-MEMS process to fabricate wax mold.

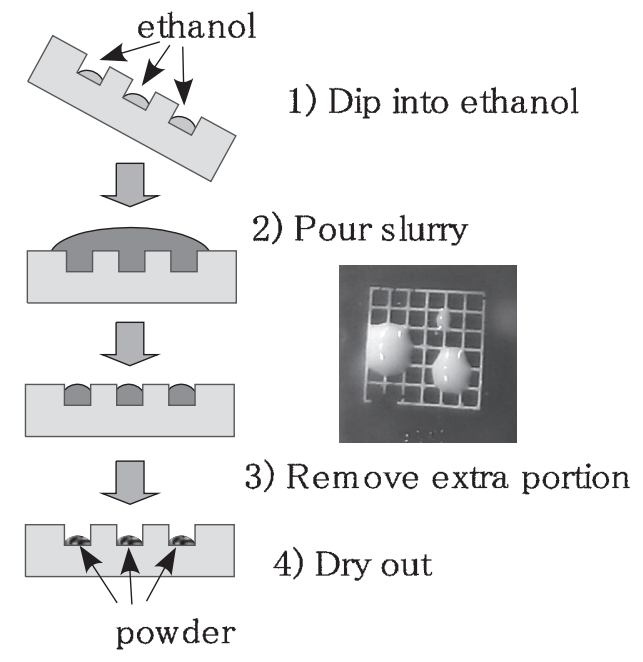

Fig.2 Filling process with slurry.
粉末が充填された型は, 同じく固形ワックスで作製された 平らな蓋を重衫られ Fig.3に示す金型内に装填され加圧され る.金型にはバンドヒーターが設置され温度制御が行われる。 ワックスの漏れを防ぐため, ワックスモールドの上下にはシ リコンゴムで作製したシールが設置されている. 圧力および 温度はFig.4に示す条件で制御した. 加圧前, ワックスは $43^{\circ} \mathrm{C}$ に加熱され十分に軟化させた。 その後最高圧 $100 \mathrm{MPa}$ まで加 圧し $60 \mathrm{~s}$ 保持した. 除荷時には圧力 $30 \mathrm{MPa}$ で保持し温度を上 昇させ $80^{\circ} \mathrm{C}$ としワックスを溶解させ, 常圧にて成形体を液化

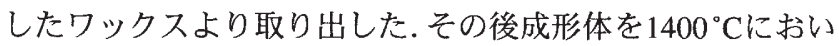
て焼結した。

\section{3 成形実験結果}

Fig.5に本研究で用いたガラスマスクパターンを示す. Fig.5 (a) は線幅 $100 \mu \mathrm{m}$, 線間隔 $4 \mathrm{~mm}$ の $7 \times 7$ の格子状のパターンで ある. Fig.5 (b) の中央部は線幅 $250 \mu \mathrm{m}$, 線間隔 $2.5 \mathrm{~mm}$ の格子 状パターン，上部はリングを連ねたパターン，下部は円孔を 配置したパターンである.このマスクを用い, 前述のプロセ スによりマスクの黒色部形状がキャビティとなったワックス モールドを得た．充填に用いるスラリーとしてはアルミナ，

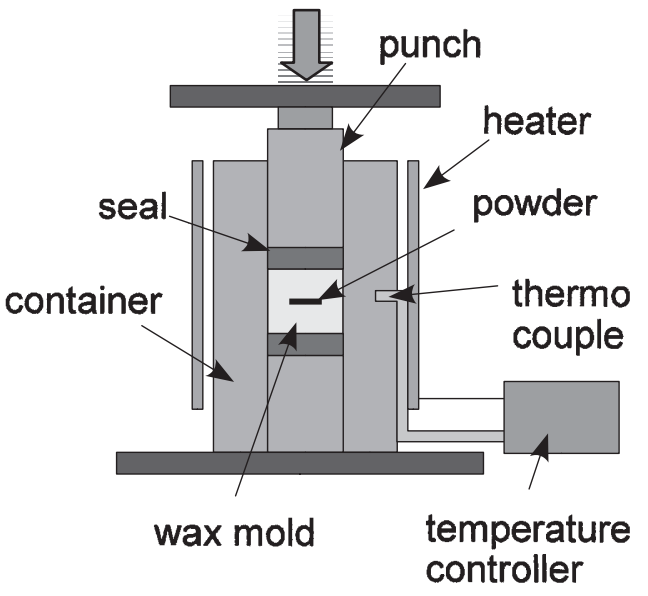

Fig.3 Schematic view of experimental apparatus.

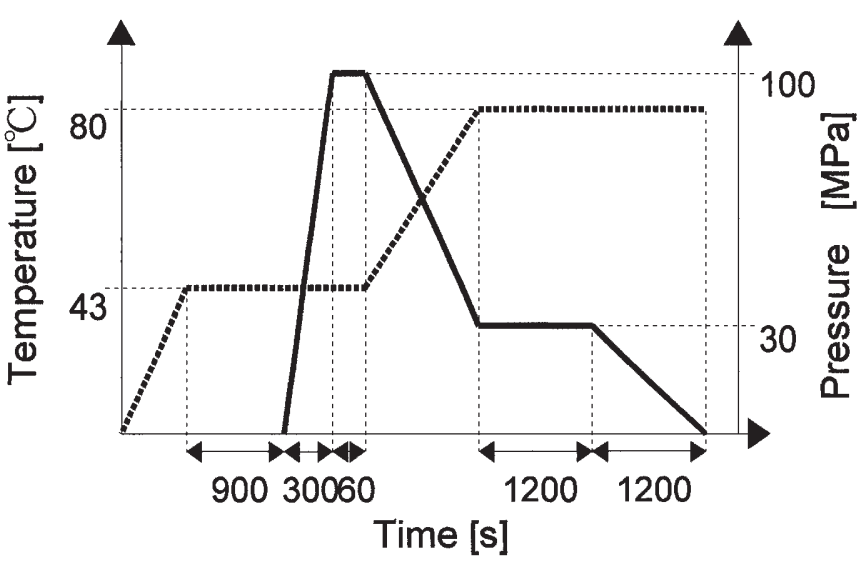

Fig.4 Process conditions. 


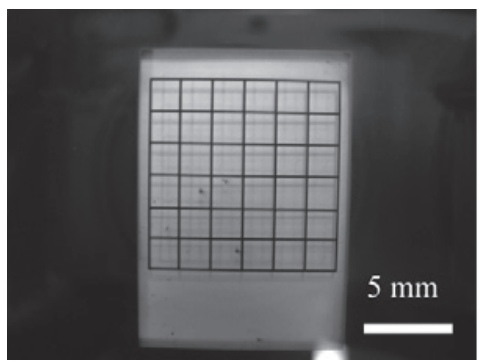

(a)

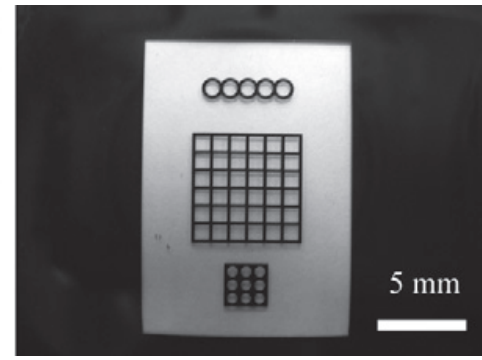

(b)

Fig.5 Glass mask patterns, (a) lattice pattern and (b) connected rings, lattice and square with nine-holes patterns.

Table 1 Relative proportion of slurries in weight.

\begin{tabular}{|c|c|c|c|c|}
\hline Slurry & $\mathrm{Al}_{2} \mathrm{O}_{3}$ & Water & PAS & PEG \\
\hline $\mathrm{A}$ & 4 & 4 & 3 & 1 \\
\hline $\mathrm{B}$ & 6 & 4 & 3 & 1 \\
\hline $\mathrm{C}$ & 8 & 4 & 3 & 1 \\
\hline $\mathrm{D}$ & 10 & 4 & 3 & 1 \\
\hline E & 11 & 4 & 3 & 1 \\
\hline
\end{tabular}

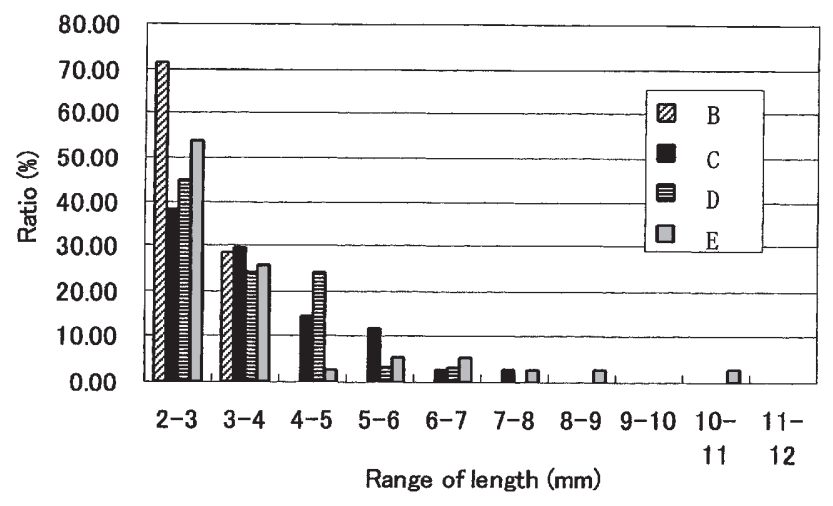

Fig.6 Histogram of length of broken parts of the compact.

水, PAS, PEG, の重量比率を $4: 4: 3: 1 \sim 11: 4: 3: 1$ の範囲 でアルミナの量を変化させたものを 5 種用意し, Table 1 に示 すように，それぞれをスラリー A, B, C, D, E と呼ぶ.

まず,Fig.5 (a)の格子形状での成形実験結果を示す.この場 合，成形体はすべて破壊され破片となった。破片のサイズを

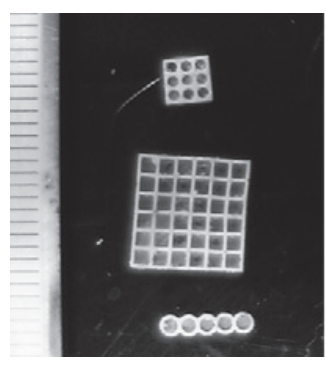

(a) Slurry A (4:4:3:1)

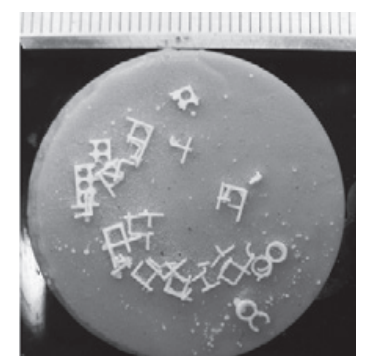

(b) Slurry E (11:4:3:1)
Fig.7 Compacted samples.

ヒストグラムで表示した結果をFig.6に示す. スラリー中のア ルミナ粉末量の違いにより破片サイズの分布は変化している. アルミナ量が増加するにつれ, 破片サイズはより大きな破片 を含み, 粉末成分の増加が良好な成形性へとつながっている.

続いてFig.5 (b)のマスクパターンを利用して作製された型 による成形結果を示す. Fig.5 (b)の型はFig.5 (a)の型と比較し 線幅が広く, パターン自体は小さいものである. Fig.7にスラ リーAおよびEより作製した成形体の写真を示し, Table 2 に は成形結果を示す，その結果，アルミナ量の最も多いスラ リーを用いたもの以外は概ね良好な成形体を得ることができ た.この結果は前述の成形実験とはまったく反対の結果であ る. 本研究の充填プロセスは最終的にスラリーが乾燥した状 態で終了する. すなわち, 粉末自体の密度は低下し成形後の 線幅も滅少するということである. Fig.5 (a)の格子型は(b) と

Table 2 Results of compaction experiments.

\begin{tabular}{|c|c|c|c|c|c|}
\hline & $\mathrm{A}(4: 4: 3: 1)$ & $\mathrm{B}(6: 4: 3: 1)$ & $\mathrm{C}(8: 4: 3: 1)$ & $\mathrm{D}(10: 4: 3: 1)$ & $\mathrm{E} \mathrm{(11:4:3:1)}$ \\
\hline Lattice & $\bigcirc$ & $\bigcirc$ & $\triangle$ & $\bigcirc$ & $\bigcirc$ \\
\hline Rings & $\bigcirc$ & $\bigcirc$ & $\bigcirc$ & $\bigcirc$ & $\times$ \\
\hline Plate with circular holes & $\bigcirc$ & $\bigcirc$ & $\bigcirc$ & $\bigcirc$ & $\times$ \\
\hline
\end{tabular}

$\bigcirc$ : completed, $\triangle$ : partially broken, $\quad \times$ : broken 


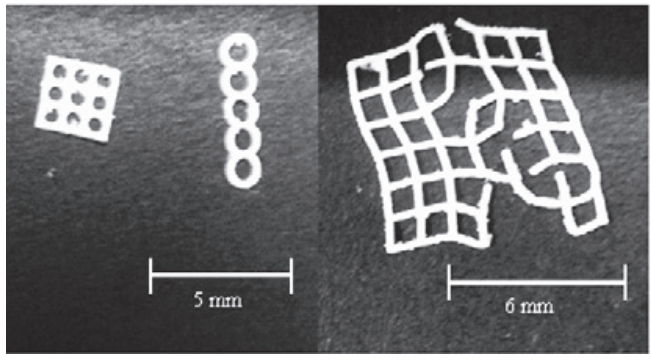

(a) Slurry A $(4: 4: 3: 1)$

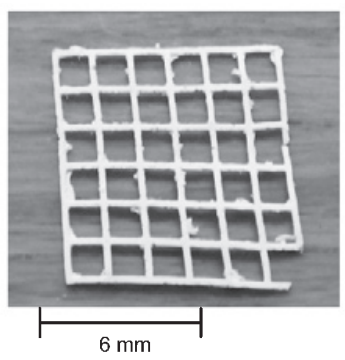

(b) Slurry B $(6: 4: 3: 1)$

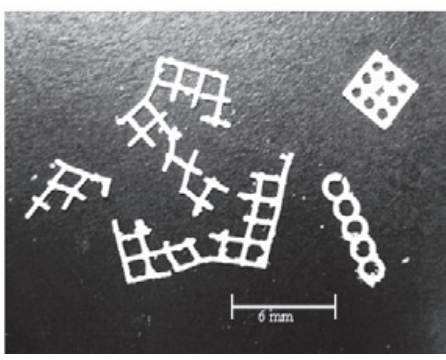

(c) Slurry C $(8: 4: 3: 1)$

Fig.8 Sintered samples.

比較し大型で溝幅も小さく,このような厳しい条件下では粉 末成分の増大が良好な成形性とつながる. 線幅がより大きな (b) の型の場合，粉末成分が少ないスラリーの方が PEG 等の 添加剤による潤滑や可塑性の影響が出ることにより, 成形性 が向上すると考えられる。

\section{4 焼結}

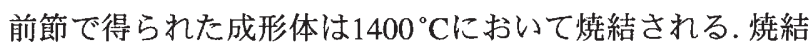
例を Fig.8に示す. 比較的小型の格子状パターン以外(連結り ングおよび円孔付平板 ) は，どのスラリーから作製した成形 体も良好な焼結体を得ることができた。しかし，格子状パ ターンにおいては写真に示されるようにスラリー中の粉末量 が少ないスラリーAの場合には大きな歪みが生じた. また, スラリーC, Dにおいては割れが発生した.スラリーBにおい てのみ概ね良好な焼結体を得ることができた。粉末分の少な いスラリーA の場合, 相対的に PAS や PEGが多く含まれる こととなり, 加熱時にこれらが除去される際に大きな歪みを 伴ったものと考えられる. スラリーC以上に粉末分の多い材 料の場合の割れは，バインダ分が不足がちになるため, 成形 時に成形体内部に既に欠陥が生じていたことが原因と考えら れる.この結果よりスラリー調整時の樹脂分が焼結の成否に 影響していることが示唆される.

\section{5 結 言}

新たに開発した温度制御を用いた半固形粉体成形法を用い, 微細構造体を作製した。ソフトMEMS 技術を応用して固形
ワックス型を作製し，粉末の充填にはスラリーを利用した. スラリーの組成が成形および焼結の成否に大きく影響するこ とが示された，スラリーの調整を検討することにより，さら に微細な構造体を作製することも可能と考えられる.

\section{謝 辞}

本研究の遂行に当たって, 京都大学大学院工学研究科マイ クロエンジニアリング専攻の故島進教授より多大な御指導を いただきました。ここに梁く感謝の意を表します。

\section{文献}

1) F.Tsumori, H.Kume, A.Kakitsuji, H.Miyamoto and S.Shima: "Semi-solid Mold Isostatic Compaction", International Journal of Powder Metallurgy, 39-8(2003)46-51.

2) F.Tsumori: "Development of Bingham semi-solid/fluid Isostatic Pressing Powder Compaction Process", J. Jpn. Soc. Powder Powder Metallurgy, 52(2005)442-445.

3) F.Tsumori: "Development of Temperature Controlled Bringham Semi-solid/fluid Isostatic Pressing (BIP) Method", J. Jpn. Soc. Powder Powder Metallurgy, 53(2006)880-884.

4) S.Matsuzaki, S.Tanaka and K.Nishiyabu: "Fabrication Method of Micro Structured Parts by Metal Injection Molding with LIGA process", J. Jpn. Soc. Powder Powder Metallurgy, 53(2005) 55-59.

5) R.Zauner: "Micro powder injection moulding", Microelectronic Engineering, 83-4-9(2005) 1442-1444. 